\title{
Review Article \\ Role of Interleukin- (IL-) 17 in the Pathogenesis and Targeted Therapies in Spondyloarthropathies
}

\author{
I-Tsu Chyuan ${ }^{1,2}$ and Ji-Yih Chen (i) ${ }^{3,4}$ \\ ${ }^{1}$ Department of Internal Medicine, Cathay General Hospital, Taipei, Taiwan \\ ${ }^{2}$ Graduate Institute of Clinical Medicine, College of Medicine, National Taiwan University, Taipei, Taiwan \\ ${ }^{3}$ Department of Medicine, Division of Allergy, Immunology and Rheumatology, Chang Gung Memorial Hospital, Taoyuan, Taiwan \\ ${ }^{4}$ College of Medicine, Chang Gung University, Taoyuan, Taiwan
}

Correspondence should be addressed to Ji-Yih Chen; jychen31@cgmh.org.tw

Received 2 July 2017; Revised 18 December 2017; Accepted 31 December 2017; Published 12 February 2018

Academic Editor: Mirella Giovarelli

Copyright (c) 2018 I-Tsu Chyuan and Ji-Yih Chen. This is an open access article distributed under the Creative Commons Attribution License, which permits unrestricted use, distribution, and reproduction in any medium, provided the original work is properly cited.

\begin{abstract}
Spondyloarthropathy $(\mathrm{SpA})$ is a unique type of joint inflammation characterized by coexisting erosive bone damage and pathological new bone formation. Previous genetic association studies have demonstrated that several cytokine pathways play a critical role in the pathogenesis of ankylosing spondylitis (AS), psoriatic arthritis (PsA), and other types of SpA. In addition to several well-known proinflammatory cytokines, recent studies suggest that IL-17 plays a pivotal role in the pathogenesis of SpA. Further evidence from human and animal studies have defined that IL-17 and IL-17-producing cells contribute to tissue inflammation, autoimmunity, and host defense, leading to the following pathologic events associated with SpA. Recently, several clinical trials targeting IL-17 pathways demonstrated the positive response of IL-17 blockade in treating AS, indicating a great potential of IL-17-targeting therapy in SpA. In this review article, we have discussed the contributing role of IL-17 and different IL-17-producing cells in the pathogenesis of SpA and provided an outline of therapeutic application of the IL-17 blockade in the treatment of SpA. Other targeted cytokines associated with IL-17 axis in SpA will also be included.
\end{abstract}

\section{Introduction}

Spondyloarthropathies (SpA) represent a group of chronic inflammatory conditions, involving mainly the axial skeleton (spine and sacroiliac joints), and share a close association with HLA-B27. Ankylosing spondylitis (AS) is the prototypical form of human SpA and characterized in acute and chronic spinal inflammation initiating from sacroiliac joints eventually leading to joint ankylosis [1]. Extensive genomewide association studies have demonstrated a great number of novel genetic associations beyond HLA-B27 pointing toward inflammatory cytokine pathways in the pathogenesis of AS and other types of human SpA [2, 3], suggesting the role of inflammatory cytokines in the pathogenesis and potential therapeutic application in SpA. Tumor necrosis factor (TNF), interleukin- (IL-) 1, IL-6, and IL-23/IL-17 are major inflammatory cytokine pathways of great interest from serial studies of single nucleotide polymorphisms, cytokine receptors, and associated intracellular signaling molecules. Among these inflammatory cytokines, IL-17 plays a dominant role in the inflammatory and proliferative cascades of human SpA $[4,5]$. In this review, we have discussed the contributing role of the IL-17 pathways in the pathophysiology of SpA from current evidence of genetic associations, studies in animal models, and expression of IL-17 in human SpA. Therapeutic effects of the IL-17 blockade in human SpA have also been discussed.

\section{IL-17 and Its Receptors}

The $I 117$ gene and IL-17 protein were first discovered from rodent and initially termed as cytotoxic $\mathrm{T}$ lymphocyteassociated antigen 8 (CTLA8) [6]. IL-17A is the founding member of the six IL-17 family cytokines (IL-17A to IL17F) [7-9]. The IL-17 protein consists of 150 amino acids with a molecular weight of $15 \mathrm{kDa}$, and its gene lies on 
human chromosome 6p12. Among IL-17 family members, IL-17A and IL-17F are dominant proinflammatory cytokines; they share 55\% amino acid resemblance and exist as either disulfide-linked homodimers or heterodimers (IL-17A/F) [9, 10]. Receptors of IL-17 are a heteromeric complex and consist of IL-17RA, IL-17RB, IL-17RC, IL-17RD, and IL-17RE $[11,12]$. IL-17 receptors contain conserved structural motifs including an extracellular fibronectin III-like domain and a cytoplasmic SEFIR domain. IL-17A and IL-17F form a homodimer or heterodimer to bind IL-17RA and IL-17RC heterodimeric complexes, thus activating downstream IL-17 receptor intracellular signaling, including nuclear factor $-\kappa \mathrm{B}(\mathrm{NF}-\kappa \mathrm{B})$, CCAAT/enhancerbinding proteins (C/EBPs) $\mathrm{C} / \mathrm{EBP} \beta$ and $\mathrm{C} / \mathrm{EBP} \delta$, mitogenactivated protein kinases (MAPKs), and JAK-PI3K and JAK-STAT pathways, to induce antibacterial peptides, proinflammatory chemokines and cytokines, and matrix metalloproteinases (MMPs) for the inflammatory pathogenesis of autoimmune diseases and host defense [13, 14]. IL-17RA is expressed in almost every cell type, including epithelial cells, endothelial cells, fibroblasts, and myeloid cells whilst IL-17RC seems to be a more restricted expression in specific cell types [15].

\section{Signal Transduction of IL-17}

It is now well known that IL-17 can activate the nuclear factor- (NF-) $\kappa \mathrm{B}$ pathway [16], and the IL-17A-mediated $\mathrm{NF}-\kappa \mathrm{B}$ activation is dependent on tumor necrosis factor receptor-associated factor 6 (TRAF6) [17]. Act1, a critical intermediate adaptor between IL-17RA and TRAF6, is recruited after IL-17A stimulation and binds to IL-17RA through SEFIR-dependent interactions [18]. In addition, the TRAF6-binding motif of Act1 further enables it to bind TRAF6 and TGF- $\beta$-activated kinase 1 to deliver downstream signals, resulting in activation of the canonical NF- $\kappa \mathrm{B}$ pathway. Moreover, Act1 can also activate the mitogenactivated protein kinase pathway to stabilize several mRNAs encoding proinflammatory cytokines and chemokines [19]. IL-17-mediated signaling not only promotes proinflammatory cascades but also triggers several regulatory pathways. IL-17A stimulation can recruit TRAF4 to the IL-17 receptor complex, and TRAF4 can be a negative modulator of IL-17mediated signaling by competing with TRAF6 for Act1 binding [20]. TRAF3 has also been shown to be another negative regulator with a similar action on the IL-17 signaling cascade [21]. Other phosphorylation events, such as phosphorylation of C/EBP $\beta$ by ERK and glycogen synthase kinase $3 \beta$ (GSK3 $\beta$ ), can also lead to inhibition of IL-17-dependent proinflammatory gene induction $[22,23]$.

\section{Sources of IL-17}

IL-17A was first cloned from CD4+ T cells, and subsequent evidence suggested the IL-17A-producing CD4+ T cells were distinct from interferon- $\gamma$ - (IFN $\gamma$-) producing effector T cells $[24,25]$. Moreover, these unique subpopulations of CD4+ T cells that produce IL-17 were driven by IL-23 and thus named as Th17 cells [26, 27]. Indeed, these
IL-17-producing CD4+ T cells (Th17 cells) were distinct from Th1 and Th2 cells and could develop independently of STAT4 and STAT6, confirming this new T cell subset in the production of IL-17 [28, 29]. Besides Th17 cells, another $\mathrm{T}$ cell subset, $\gamma \delta \mathrm{T}$ cells, can respond to IL-23, thus amplifying Th17 responses [30] and producing IL-17 in certain circumstances [31]. In addition to T cells, other IL-17-producing cells include natural killer (NK) cells, mast cells, neutrophils, and innate lymphoid cells; these IL-17producing cells can produce IL-17 in a specific inflammatory condition possibly through genetic programming [32-35]. Although several animal and human studies suggest these cells produce IL-17 in response to inflammation, the respective contributions of these different cell types to the disease pathology remain to be explored. This raises a critical question for the targeted role of IL-17 in inflammation according to cell-type and disease-type specificity.

\section{Function of IL-17}

The major biological activity of IL-17 is involved in promoting inflammation as earlier studies demonstrated that IL-17 triggers the IL- 6 production of synoviocytes from patients with rheumatoid arthritis and this effect is even more enhanced when in synergy with other proinflammatory cytokines (IL-1, TNF) [24, 36, 37]. In addition, IL-17 in chronic inflammation contributes to inhibition of matrix production in chondrocytes and osteoblasts through activating MMPs, resulting in joint destruction and defective tissue repair [38]. IL-17 also increases the expression of receptor activator of NF- $\kappa \mathrm{B}$ ligand (RANKL) on osteoblasts and in turn increases RANK signaling in osteoclasts [39-41]. These studies link IL-17 activity to bone destruction, suggesting the potential role of IL-17 in osteoimmunology. In intestinal inflammation, IL-17 also stimulates MMPs, IL6, and IL-8 production from colonic subepithelial myofibroblasts in vitro [42]. In the central nervous system, IL-17 can disrupt the blood-brain barrier tight junction and further facilitates local migration of CD4 T cells, leading to neuroinflammation [43]. All these results support the role of IL-17 in the pathogenesis of tissue-specific and systemic autoimmune diseases.

\section{IL-17 in AS}

Accumulated evidences have demonstrated IL-17 and Th17 effector responses are involved in inflammatory spondyloarthritic condition, including AS, psoriatic arthritis (PsA), reactive arthritis, and undifferentiated spondyloarthritis, suggesting Th17-associated pathways including IL-23R are genetically associated with AS susceptibility [44-46]. A key question to IL-17 in the pathogenesis of SpA is how IL-17 drives inflammation leading to erosive bone damage and pathological new bone formation.

AS is the prototypical form of human SpA and is characterized by joint inflammation, leading to the formation of ectopic new bone and eventually progressive ankylosis of sacroiliac joints. AS has shown a strong genetic association with IL-23R polymorphisms with functional relevance in $\mathrm{T}$ cell immune response [44, 47, 48], suggesting genetic 
variations in the IL-23/IL-17 axis may influence the effector function of Th17 cells in patients with AS. In addition, TNFSF15, TRADD, and CARD9 genes were also reported to be important in the regulation of Th17 cell development and proliferation $[49,50]$. Uddin et al. used multiple integrated genomic approaches and identified AS risk alleles that overlap with global immune-related pathways and Th17-related genes [51]. These genetic data results indicate that IL-17 and Th17 effector responses are influenced by both genetic and upstream signal modulation to amplify and perpetuate inflammation.

The importance of IL-17 in the pathogenesis of AS was further defined in several animal and human observational studies. Mice with overexpression of IL-23 represented axial and peripheral enthesitis, and entheseal new bone formation, which is similar to human AS; blockade of the downstream effector cytokine IL-17 significantly reduced disease [52]. IL-17-deficient mice exhibit less joint inflammation in an inflammatory arthritis model [53], and IL-17 receptordeficient mice also showed decreased proinflammatory cytokine production in the synovium which prevents cartilage destruction [54]. In human AS, IL-17 and IL-23 were elevated in the serum of patients compared to controls and the production IL-17 was even more enhanced when stimulated with IL-23 [55, 56]. Chen et al. also reported similar results of elevated levels of IL-17 and IL-23 in AS patients and further observed that the levels correlate to disease activity measured by Bath Ankylosing Spondylitis Disease Activity Index (BASDAI) scores [57]. These observation studies suggest IL-17 may contribute to the pathogenesis of AS.

Th17 cells are the main cell type in the production of IL-17, and Th17 cells were observed to increase in the blood from patients with AS [58, 59]. Th17 cells specifically expressing KIR3DL2 could respond to the HLA-B27 homodimer and increased in number in AS patients [60]. In addition to Th17 cells, other IL-17-producing T cell subsets have also been identified to be specifically upregulated in AS. For example, increased circulating IL-17-producing IL-23R $+\gamma \delta \mathrm{T}$ cells were observed in patients with active AS [61]. Furthermore, mast cells were observed to express more IL-17 in SpA and constituted the major IL-17-expressing cell population in the SpA synovium [62]. Increased expression of IL-17 was found predominantly in $\mathrm{MPO}+$ cells and in CD15+ neutrophils in the subchondral bone marrow of inflamed spine from AS patients [4]. All these results suggest that both the innate and adaptive mechanisms drive AS pathogenesis and IL-17-mediated inflammation of AS joints may be tissue- and cell-type specific.

Several antibodies blocking the IL-17/IL-17 receptors have been developed and examined in clinical trials in AS patients over the past few years. At least three monoclonal antibodies have been developed to neutralize IL-17 or block IL-17 receptor signaling: secukinumab (anti-IL-17A), ixekizumab (anti-IL-17A), and brodalumab (anti-IL-17RA). Secukinumab is a fully human monoclonal antibody that selectively binds and neutralizes IL-17. In an earlier phase II clinical trial, secukinumab showed good efficacy in controlling symptoms of AS [63]. Subsequent two large placebo-controlled phase III trials provide further proof of its efficacy in the inhibition of disease activity, similar to what has been seen in previous TNF-blocker trials [64]. Moreover, the drug was superior to placebo both in patients that were naive and in those that had not responded to previous anti-TNF treatment, suggesting the IL-17 pathway inhibits inflammation distinct from that in TNF [65]. Similarly to secukinumab, ixekizumab is another humanized monoclonal antibody that binds and neutralizes IL-17A, and a phase III trial in AS is ongoing (identifier: NCT02696798). Brodalumab is a fully human anti-IL17 RA antibody that inhibits the biological activity of IL-17A, IL-17F, and other IL-17 family members, and a phase III trial in AS is ongoing (identifier: NCT02985983).

Patients with spondyloarthritis exhibit excessive bone formation followed by joint inflammation that can occur at entheses (enthesophytes), near joints on the periosteal surface (osteophytes), or in the spine (syndesmophytes). Whether IL-17 inhibitor treatment might have an effect on the radiographic progression of bone formation and destruction in AS remains to be determined. A recent randomised phase III study on the evaluation of radiographic outcomes of secukinumab in AS shows a low mean progression of spinal radiographic changes over 2 years [66]. However, this secukinumab study did not include a control group. In addition, the effects of blocking IL-17A on periosteal bone formation have not yet been evaluated. Therefore, there is still no firm conclusion about the effects of IL-17 inhibition therapy on radiographic disease progression.

\section{IL-17 in PsA}

PsA belongs to SpA and is characterized by the involvement of the skin (psoriatic plaque), nails, and peripheral and axial joints as well as occasional enthesitis $[67,68]$. PsA develops in approximately $25 \%$ of psoriasis patients [69], suggesting that the link of psoriasis and PsA may be through a similar immune mechanism and that they share collective pathological events and clinical features. The genetic variations on the IL-23/IL-17 signaling pathway affect the effector function of Th1, and Th17 cells may contribute to the pathogenesis of AS and other SpA [70, 71], and a single nucleotide polymorphism (SNP) in IL-23A and IL-23R has also been shown in association with PsA [72, 73], suggesting that the IL-23/ IL-17 pathway may share common genetic background in developing SpA.

Accumulating studies have evidenced the critical role of IL-17 in the pathogenesis of PsA. There were an increased expression of IL-17 observed from psoriatic skin compared to the nonlesioned psoriatic skin, and the upregulation of IL-17 was positively associated with psoriatic disease severity $[74,75]$. Fibroblast-like synoviocytes (FLS) from PsA synovium produce more proinflammatory cytokines and MMPs upon IL-17 stimulation [76]. As mentioned earlier, IL-17 can promote osteoclastogenesis resulting in bone erosion through activating the expression of RANKL $[77,78]$, which can be partially explained by the destructive bone lesions in PsA. All these results suggest IL-17 triggers both skin and joint pathology and inflammation in PsA. The source of 
IL-17 in psoriatic skin and inflamed joint has been investigated from several observational study results. Th17 cells were observed to have an increased number in both blood and skin lesions from PsA patients, which was also positively correlated with disease activity [79, 80]. In PsA synovium, there were increased IL-17-producing CD4+ effector memory $\mathrm{T}$ cell aggregation and expression of functionally active IL-17RA [76]. Other IL-17-producing cells, including mast cells and neutrophils, also represent additional sources of IL-17-mediating psoriasis progression [81]. IL-17-producing mast cells are increased in the synovial fluid of patients with psoriatic arthritis [82] and NKp44+ ILC3 cells are also increased in the peripheral blood and skin in psoriasis [83] and produce IL-17 [84], indicating the IL-17-rich milieu in the inflamed skin and joints of PsA resulting from multiple innate and adaptive IL-17-producing cells. This concept is further confirmed in the murine model of aldara-induced psoriasis, where both skin-invading population of $\gamma \delta \mathrm{T}$ cells and $\mathrm{ROR} \gamma \mathrm{t}$ CD3-innate lymphocytes which could produce IL-17 contribute to the initiation of psoriasiform plaque formation [85]. Taken together, both IL-17 and IL-17-producing cells contribute to multiple cytokine network and play a pivotal role in the pathogenesis of PsA.

Therapeutic blockade of IL-17 works very well for psoriasis and is relatively good for PsA. In psoriasis, phase III clinical trials for secukinumab have demonstrated that IL-17 inhibition therapy can achieve a 75\% improvement of the Psoriasis Area and Severity Index (PASI75) in more than $75 \%$ of patients with plaque psoriasis response, and a significant portion of the patients also achieved PASI90 and PASI100 responses $[86,87]$. Similar to secukinumab, around $80 \%$ to $90 \%$ of patients treated with ixekizumab $[88,89]$ and brodalumab $[90,91]$ achieved a PASI75 response, indicating that the IL-17 pathway is critical for keratinocytes and infiltrating immune cells in the skin of psoriasis. As for PsA, IL-17 inhibition therapy seems to have a modest effect on the inhibition of joint inflammation and bone destruction. In a phase II clinical trial for secukinumab in patients with moderate-to-severe PsA, a trend towards improvement was demonstrated in the secukinumab group although it did not meet statistical significance [92]; a subsequent phase III clinical trial is ongoing to verify its efficacy in PsA (identifier: NCT02771210). Although a phase III clinical trial for brodalumab in PsA was halted initially because of increased suicidal ideation and suicide events in previous psoriasis clinical trials [90], a phase III trial for brodalumab in axial SpA is ongoing (identifier: NCT02985983).

\section{Other Targeted Cytokines Associated with IL-17 Axis in SpA}

Previous studies have shown that IL-23 can trigger and drive Th17 responses by expansion of Th17 cells and thus an increase in IL-17 levels. Ustekinumab, a monoclonal antibody against the p40 subunit of IL-12 and IL-23, has shown to be beneficial in the treatment of AS, with improvement of clinical disease score, patient-reported outcome parameters, and MRI score [93], suggesting IL-23/ IL-17-targeted therapies are very promising for SpA.

IL-17 is the main cytokine of Th17 cells; nevertheless, Th17 cells can also produce some other cytokines including IL-22 [94, 95]. IL-22 belongs to the IL-10 family and is released by several types of CD4+ and CD8+ T cells as well as natural killer $\mathrm{T}$ cells, $\gamma \delta \mathrm{T}$ cells, and type 3 ILCs [96]. The IL-17 and IL-22 expression is associated with many autoimmune processes, such as psoriasis and inflammatory bowel disease $[97,98]$. In an SpA animal model, although the development of enthesitis and entheseal new bone formation are largely influenced by IL-17/IL-23 axis, enthesitis is specifically dependent on IL-22 [99], and the IL-22producing entheseal resident cells have shown to activate osteoblast-mediated bone remodeling [52], suggesting IL-22 may coordinate with the IL-17/IL-23 pathway in inflammatory bone remodeling. Furthermore, synovial fluid of PsA patients have shown higher concentration of IL-22, and exogenous administration of IL-22 can induce marked proliferation of PsA-derived fibroblast-like synoviocytes [100]. A recent study has further demonstrated that IL-22 increases the proliferation and migration of the human mesenchymal stem cell (MSC) in inflammatory environments, and the MSC osteogenesis is enhanced following IL-22 exposure [101]. All these results suggest the potential role of IL-22 in addition to the IL-17/IL-23 axis in bone remodeling and provide a novel pathway for exploring pathological and inflammatory osteogenesis in SpA.

\section{Conclusions}

In summary, accumulated evidence supports the critical role of IL-17 and IL-17-producing cells in the joint inflammation, cartilage damage, and bone remodeling associated with SpA. Animal models as well as human genetic and observation studies provided strong mechanistic rationales for targeting IL-17-associated pathways in the treatment of SpA. Several clinical trials showed that blockade of IL-17 successfully restores joint inflammation and remodeling in $\mathrm{SpA}$, providing effective and well-tolerated alternatives to conventional treatment in SpA.

\section{Conflicts of Interest}

The authors have no conflicts of interest to declare.

\section{Acknowledgments}

This work was supported by grants from the National Science Council, Taiwan (105-2628-B-281-001-MY3). Dr. Chen's work was supported by Chang Gung Memorial Hospital (CMRPG3B1823 and CMRPG3E0533).

\section{References}

[1] M. Dougados and D. Baeten, "Spondyloarthritis," The Lancet, vol. 377, no. 9783, pp. 2127-2137, 2011.

[2] K. McHugh and P. Bowness, "The link between HLA-B27 and SpA-new ideas on an old problem," Rheumatology, vol. 51, no. 9, pp. 1529-1539, 2012. 
[3] K. Vandenbroeck, "Cytokine gene polymorphisms and human autoimmune disease in the era of genome-wide association studies," Journal of Interferon \& Cytokine Research, vol. 32, no. 4, pp. 139-151, 2012.

[4] H. Appel, R. Maier, P. Wu et al., "Analysis of IL- $17^{+}$cells in facet joints of patients with spondyloarthritis suggests that the innate immune pathway might be of greater relevance than the Th17-mediated adaptive immune response," Arthritis Research \& Therapy, vol. 13, no. 3, article R95, 2011.

[5] J. R. Vidal-Castiñeira, A. López-Vázquez, R. Diaz-Peña et al., "A single nucleotide polymorphism in the Il17ra promoter is associated with functional severity of ankylosing spondylitis," PLoS One, vol. 11, no. 7, article e0158905, 2016.

[6] E. Rouvier, M. F. Luciani, M. G. Mattei, F. Denizot, and P. Golstein, "CTLA-8, cloned from an activated T cell, bearing AU-rich messenger RNA instability sequences, and homologous to a herpesvirus saimiri gene," The Journal of Immunology, vol. 150, no. 12, pp. 5445-5456, 1993.

[7] H. Li, J. Chen, A. Huang et al., "Cloning and characterization of IL-17B and IL-17C, two new members of the IL-17 cytokine family," Proceedings of the National Academy of Sciences of the United States of America, vol. 97, no. 2, pp. 773-778, 2000.

[8] J. Lee, W. H. Ho, M. Maruoka et al., "IL-17E, a novel proinflammatory ligand for the IL-17 receptor homolog IL-17Rh1," The Journal of Biological Chemistry, vol. 276, no. 2, pp. 1660-1664, 2001.

[9] S. G. Hymowitz, E. H. Filvaroff, J. P. Yin et al., "IL-17s adopt a cystine knot fold: structure and activity of a novel cytokine, IL-17F, and implications for receptor binding," The EMBO Journal, vol. 20, no. 19, pp. 5332-5341, 2001.

[10] S. C. Liang, A. J. Long, F. Bennett et al., "An IL-17F/A heterodimer protein is produced by mouse Th17 cells and induces airway neutrophil recruitment," The Journal of Immunology, vol. 179, no. 11, pp. 7791-7799, 2007.

[11] L. K. Ely, S. Fischer, and K. C. Garcia, "Structural basis of receptor sharing by interleukin 17 cytokines," Nature Immunology, vol. 10, no. 12, pp. 1245-1251, 2009.

[12] D. Toy, D. Kugler, M. Wolfson et al., "Cutting edge: interleukin 17 signals through a heteromeric receptor complex," The Journal of Immunology, vol. 177, no. 1, pp. 36-39, 2006.

[13] K. Hirota, J. H. Duarte, M. Veldhoen et al., "Fate mapping of IL-17-producing T cells in inflammatory responses," Nature Immunology, vol. 12, no. 3, pp. 255-263, 2011.

[14] M. Veldhoen, "Interleukin 17 is a chief orchestrator of immunity," Nature Immunology, vol. 18, no. 6, pp. 612-621, 2017.

[15] D. Ge and Z. You, "Expression of interleukin-17RC protein in normal human tissues," International Archives of Medicine, vol. 1, no. 1, p. 19, 2008.

[16] Z. Yao, W. C. Fanslow, M. F. Seldin et al., "Herpesvirus Saimiri encodes a new cytokine, IL-17, which binds to a novel cytokine receptor," Immunity, vol. 3, no. 6, pp. 811-821, 1995.

[17] R. Schwandner, K. Yamaguchi, and Z. Cao, "Requirement of tumor necrosis factor receptor-associated factor (TRAF) 6 in interleukin 17 signal transduction," The Journal of Experimental Medicine, vol. 191, no. 7, pp. 1233-1240, 2000.

[18] Y. Qian, C. Liu, J. Hartupee et al., "The adaptor Act1 is required for interleukin 17-dependent signaling associated with autoimmune and inflammatory disease," Nature Immunology, vol. 8, no. 3, pp. 247-256, 2007.
[19] J. Hartupee, C. Liu, M. Novotny, X. Li, and T. Hamilton, "IL-17 enhances chemokine gene expression through mRNA stabilization," The Journal of Immunology, vol. 179, no. 6, pp. 4135-4141, 2007.

[20] J. A. Zepp, C. Liu, W. Qian et al., "Cutting edge: TNF receptor-associated factor 4 restricts IL-17-mediated pathology and signaling processes," Journal of Immunology, vol. 189, no. 1, pp. 33-37, 2012.

[21] S. Zhu, W. Pan, P. Shi et al., "Modulation of experimental autoimmune encephalomyelitis through TRAF3-mediated suppression of interleukin 17 receptor signaling," The Journal of Experimental Medicine, vol. 207, no. 12, pp. 2647-2662, 2010.

[22] F. Shen, N. Li, P. Gade et al., "IL-17 receptor signaling inhibits $\mathrm{C} / \mathrm{EBP} \beta$ by sequential phosphorylation of the regulatory 2 domain," Science Signaling, vol. 2, no. 59, article ra8, 2009.

[23] A. Maitra, F. Shen, W. Hanel et al., "Distinct functional motifs within the IL-17 receptor regulate signal transduction and target gene expression," Proceedings of the National Academy of Sciences of the United States of America, vol. 104, no. 18, pp. 7506-7511, 2007.

[24] F. Fossiez, O. Djossou, P. Chomarat et al., "T cell interleukin17 induces stromal cells to produce proinflammatory and hematopoietic cytokines," The Journal of Experimental Medicine, vol. 183, no. 6, pp. 2593-2603, 1996.

[25] C. Infante-Duarte, H. F. Horton, M. C. Byrne, and T. Kamradt, "Microbial lipopeptides induce the production of IL-17 in Th cells," The Journal of Immunology, vol. 165, no. 11, pp. 6107-6115, 2000.

[26] D. J. Cua, J. Sherlock, Y. Chen et al., "Interleukin-23 rather than interleukin-12 is the critical cytokine for autoimmune inflammation of the brain," Nature, vol. 421, no. 6924, pp. 744-748, 2003.

[27] C. L. Langrish, Y. Chen, W. M. Blumenschein et al., "IL-23 drives a pathogenic $\mathrm{T}$ cell population that induces autoimmune inflammation," The Journal of Experimental Medicine, vol. 201, no. 2, pp. 233-240, 2005.

[28] L. E. Harrington, R. D. Hatton, P. R. Mangan et al., "Interleukin 17-producing $\mathrm{CD}^{+}$effector $\mathrm{T}$ cells develop via a lineage distinct from the T helper type 1 and 2 lineages," Nature Immunology, vol. 6, no. 11, pp. 1123-1132, 2005.

[29] H. Park, Z. Li, X. O. Yang et al., "A distinct lineage of CD4 T cells regulates tissue inflammation by producing interleukin 17," Nature Immunology, vol. 6, no. 11, pp. 1133-1141, 2005.

[30] C. E. Sutton, S. J. Lalor, C. M. Sweeney, C. F. Brereton, E. C. Lavelle, and K. H. Mills, "Interleukin-1 and IL-23 induce innate IL-17 production from $\gamma \delta \mathrm{T}$ cells, amplifying Th17 responses and autoimmunity," Immunity, vol. 31, no. 2, pp. 331-341, 2009.

[31] B. Martin, K. Hirota, D. J. Cua, B. Stockinger, and M. Veldhoen, "Interleukin-17-producing $\gamma \delta \mathrm{T}$ cells selectively expand in response to pathogen products and environmental signals," Immunity, vol. 31, no. 2, pp. 321-330, 2009.

[32] M. L. Michel, A. C. Keller, C. Paget et al., "Identification of an IL-17-producing NK1. $1^{\text {neg }}$ iNKT cell population involved in airway neutrophilia," The Journal of Experimental Medicine, vol. 204, no. 5, pp. 995-1001, 2007.

[33] M. Pichavant, S. Goya, E. H. Meyer et al., "Ozone exposure in a mouse model induces airway hyperreactivity that requires the presence of natural killer T cells and IL-17," The Journal of Experimental Medicine, vol. 205, no. 2, pp. 385-393, 2008. 
[34] P. Milpied, B. Massot, A. Renand et al., "IL-17-producing invariant NKT cells in lymphoid organs are recent thymic emigrants identified by neuropilin-1 expression," Blood, vol. 118, no. 11, pp. 2993-3002, 2011.

[35] D. J. Cua and C. M. Tato, "Innate IL-17-producing cells: the sentinels of the immune system," Nature Reviews Immunology, vol. 10, no. 7, pp. 479-489, 2010.

[36] M. Chabaud, J. M. Durand, N. Buchs et al., "Human interleukin-17: a T cell-derived proinflammatory cytokine produced by the rheumatoid synovium," Arthritis \& Rheumatism, vol. 42, no. 5, pp. 963-970, 1999.

[37] S. Zrioual, R. Ecochard, A. Tournadre, V. Lenief, M. A. Cazalis, and P. Miossec, "Genome-wide comparison between IL-17A- and IL-17F-induced effects in human rheumatoid arthritis synoviocytes," The Journal of Immunology, vol. 182, no. 5, pp. 3112-3120, 2009.

[38] E. M. Moran, R. Mullan, J. McCormick et al., "Human rheumatoid arthritis tissue production of IL-17A drives matrix and cartilage degradation: synergy with tumour necrosis factor- $\alpha$, Oncostatin $M$ and response to biologic therapies," Arthritis Research \& Therapy, vol. 11, no. 4, article R113, 2009.

[39] P. Miossec, "Interleukin-17 in rheumatoid arthritis: if $\mathrm{T}$ cells were to contribute to inflammation and destruction through synergy," Arthritis \& Rheumatism, vol. 48, no. 3, pp. 594-601, 2003.

[40] J. P. van Hamburg, P. S. Asmawidjaja, N. Davelaar et al., "Th17 cells, but not Th1 cells, from patients with early rheumatoid arthritis are potent inducers of matrix metalloproteinases and proinflammatory cytokines upon synovial fibroblast interaction, including autocrine interleukin-17A production," Arthritis \& Rheumatism, vol. 63, no. 1, pp. 7383, 2011.

[41] M. Chabaud, P. Garnero, J. M. Dayer, P. A. Guerne, F. Fossiez, and P. Miossec, "Contribution of interleukin 17 to synovium matrix destruction in rheumatoid arthritis," Cytokine, vol. 12, no. 7, pp. 1092-1099, 2000.

[42] A. Andoh, A. Ogawa, S. Bamba, and Y. Fujiyama, "Interaction between interleukin-17-producing $\mathrm{CD}^{+} \mathrm{T}$ cells and colonic subepithelial myofibroblasts: what are they doing in mucosal inflammation?," Journal of Gastroenterology, vol. 42, Supplement 17, pp. 29-33, 2007.

[43] J. Huppert, D. Closhen, A. Croxford et al., "Cellular mechanisms of IL-17-induced blood-brain barrier disruption," The FASEB Journal, vol. 24, no. 4, pp. 1023-1034, 2010.

[44] Australo-Anglo-American Spondyloarthritis Consortium (TASC), J. D. Reveille, A. M. Sims et al., "Genome-wide association study of ankylosing spondylitis identifies nonMHC susceptibility loci," Nature Genetics, vol. 42, no. 2, pp. 123-127, 2010.

[45] R. A. Colbert, T. M. Tran, and G. Layh-Schmitt, "HLA-B27 misfolding and ankylosing spondylitis," Molecular Immunology, vol. 57, no. 1, pp. 44-51, 2014.

[46] S. K. Raychaudhuri, A. Saxena, and S. P. Raychaudhuri, "Role of IL-17 in the pathogenesis of psoriatic arthritis and axial spondyloarthritis," Clinical Rheumatology, vol. 34, no. 6, pp. 1019-1023, 2015.

[47] P. Rahman, R. D. Inman, D. D. Gladman, J. P. Reeve, L. Peddle, and W. P. Maksymowych, "Association of interleukin-23 receptor variants with ankylosing spondylitis," Arthritis \& Rheumatism, vol. 58, no. 4, pp. 1020-1025, 2008.
[48] R. Sarin, X. Wu, and C. Abraham, "Inflammatory disease protective R381Q IL23 receptor polymorphism results in decreased primary CD4+ and CD8+ human T-cell functional responses," Proceedings of the National Academy of Sciences of the United States of America, vol. 108, no. 23, pp. 95609565, 2011.

[49] E. Zinovieva, C. Bourgain, A. Kadi et al., "Comprehensive linkage and association analyses identify haplotype, near to the TNFSF15 gene, significantly associated with spondyloarthritis," PLoS Genetics, vol. 5, no. 6, article e1000528, 2009.

[50] J. J. Pointon, D. Harvey, T. Karaderi et al., "The chromosome 16q region associated with ankylosing spondylitis includes the candidate gene tumour necrosis factor receptor type 1associated death domain (TRADD)," Annals of the Rheumatic Diseases, vol. 69, no. 6, pp. 1243-1246, 2010.

[51] M. Uddin, D. Codner, S. M. Hasan, S. W. Scherer, D. D. O'Rielly, and P. Rahman, "Integrated genomics identifies convergence of ankylosing spondylitis with global immune mediated disease pathways," Scientific Reports, vol. 5, no. 1, article 10314, 2015.

[52] J. P. Sherlock, B. Joyce-Shaikh, S. P. Turner et al., "IL-23 induces spondyloarthropathy by acting on ROR- $\gamma \mathrm{t}^{+} \mathrm{CD} 3^{+-}$ CD4 ${ }^{-} \mathrm{CD}^{-}$entheseal resident $\mathrm{T}$ cells," Nature Medicine, vol. 18, no. 7, pp. 1069-1076, 2012.

[53] S. Nakae, A. Nambu, K. Sudo, and Y. Iwakura, "Suppression of immune induction of collagen-induced arthritis in IL-17deficient mice," The Journal of Immunology, vol. 171, no. 11, pp. 6173-6177, 2003.

[54] M. I. Koenders, J. K. Kolls, B. Oppers-Walgreen et al., "Interleukin-17 receptor deficiency results in impaired synovial expression of interleukin-1 and matrix metalloproteinases 3, 9, and 13 and prevents cartilage destruction during chronic reactivated streptococcal cell wall-induced arthritis," Arthritis \& Rheumatism, vol. 52, no. 10, pp. 3239-3247, 2005.

[55] Y. Mei, F. Pan, J. Gao et al., "Increased serum IL-17 and IL-23 in the patient with ankylosing spondylitis," Clinical Rheumatology, vol. 30, no. 2, pp. 269-273, 2011.

[56] X. Wang, Z. Lin, Q. Wei, Y. Jiang, and J. Gu, "Expression of IL-23 and IL-17 and effect of IL-23 on IL-17 production in ankylosing spondylitis," Rheumatology International, vol. 29, no. 11, pp. 1343-1347, 2009.

[57] W. S. Chen, Y. S. Chang, K. C. Lin et al., "Association of serum interleukin-17 and interleukin-23 levels with disease activity in Chinese patients with ankylosing spondylitis," Journal of the Chinese Medical Association, vol. 75, no. 7, pp. 303-308, 2012.

[58] L. Limon-Camacho, M. I. Vargas-Rojas, J. Vazquez-Mellado et al., "In vivo peripheral blood proinflammatory $\mathrm{T}$ cells in patients with ankylosing spondylitis," The Journal of Rheumatology, vol. 39, no. 4, pp. 830-835, 2012.

[59] H. Shen, J. C. Goodall, and J. S. Hill Gaston, "Frequency and phenotype of peripheral blood Th17 cells in ankylosing spondylitis and rheumatoid arthritis," Arthritis \& Rheumatism, vol. 60, no. 6, pp. 1647-1656, 2009.

[60] P. Bowness, A. Ridley, J. Shaw et al., "Th17 cells expressing $\mathrm{KIR} 3 \mathrm{DL} 2^{+}$and responsive to HLA-B27 homodimers are increased in ankylosing spondylitis," The Journal of Immunology, vol. 186, no. 4, pp. 2672-2680, 2011.

[61] T. J. Kenna, S. I. Davidson, R. Duan et al., "Enrichment of circulating interleukin-17-secreting interleukin-23 receptorpositive $\gamma / \delta \mathrm{T}$ cells in patients with active ankylosing 
spondylitis," Arthritis \& Rheumatism, vol. 64, no. 5, pp. 1420-1429, 2012.

[62] T. Noordenbos, N. Yeremenko, I. Gofita et al., "Interleukin17-positive mast cells contribute to synovial inflammation in spondylarthritis," Arthritis \& Rheumatism, vol. 64, no. 1, pp. 99-109, 2012.

[63] D. Baeten, X. Baraliakos, J. Braun et al., "Anti-interleukin17A monoclonal antibody secukinumab in treatment of ankylosing spondylitis: a randomised, double-blind, placebo-controlled trial," The Lancet, vol. 382, no. 9906, pp. 1705-1713, 2013.

[64] D. Baeten, J. Sieper, J. Braun et al., "Secukinumab, an interleukin-17A inhibitor, in ankylosing spondylitis," The New England Journal of Medicine, vol. 373, no. 26, pp. 2534-2548, 2015.

[65] J. Sieper, A. Deodhar, H. Marzo-Ortega et al., "Secukinumab efficacy in anti-TNF-naive and anti-TNF-experienced subjects with active ankylosing spondylitis: results from the MEASURE 2 study," Annals of the Rheumatic Diseases, vol. 76, no. 3, pp. 571-592, 2017.

[66] J. Braun, X. Baraliakos, A. Deodhar et al., "Effect of secukinumab on clinical and radiographic outcomes in ankylosing spondylitis: 2-year results from the randomised phase III MEASURE 1 study," Annals of the Rheumatic Diseases, vol. 76, no. 6, pp. 1070-1077, 2017.

[67] S. P. Raychaudhuri, “A cutting edge overview: psoriatic disease," Clinical Reviews in Allergy \& Immunology, vol. 44, no. 2, pp. 109-113, 2013.

[68] C. E. Griffiths and J. N. Barker, "Pathogenesis and clinical features of psoriasis," The Lancet, vol. 370, no. 9583, pp. 263-271, 2007.

[69] A. Amherd-Hoekstra, H. Naher, H. M. Lorenz, and A. H. Enk, "Psoriatic arthritis: a review," Journal der Deutschen Dermatologischen Gesellschaft, vol. 8, no. 5, pp. 332-339, 2010.

[70] M. Coffre, M. Roumier, M. Rybczynska et al., "Combinatorial control of Th17 and Th1 cell functions by genetic variations in genes associated with the interleukin-23 signaling pathway in spondyloarthritis," Arthritis \& Rheumatism, vol. 65, no. 6, pp. 1510-1521, 2013.

[71] P. Di Meglio, A. Di Cesare, U. Laggner et al., "The IL23R R381Q gene variant protects against immune-mediated diseases by impairing IL-23-induced Th17 effector response in humans," PLoS One, vol. 6, no. 2, article e17160, 2011.

[72] J. Bowes, G. Orozco, E. Flynn et al., "Confirmation of TNIP1 and IL23A as susceptibility loci for psoriatic arthritis," Annals of the Rheumatic Diseases, vol. 70, no. 9, pp. 1641-1644, 2011.

[73] C. Filer, P. Ho, R. L. Smith et al., "Investigation of association of the IL12B and IL23R genes with psoriatic arthritis," Arthritis \& Rheumatism, vol. 58, no. 12, pp. 3705-3709, 2008.

[74] C. Johansen, P. A. Usher, R. B. Kjellerup, D. Lundsgaard, L. Iversen, and K. Kragballe, "Characterization of the interleukin-17 isoforms and receptors in lesional psoriatic skin," British Journal of Dermatology, vol. 160, no. 2, pp. 319-324, 2009.

[75] S. B. Yilmaz, N. Cicek, M. Coskun, O. Yegin, and E. Alpsoy, "Serum and tissue levels of IL-17 in different clinical subtypes of psoriasis," Archives of Dermatological Research, vol. 304, no. 6, pp. 465-469, 2012.

[76] S. P. Raychaudhuri, S. K. Raychaudhuri, and M. C. Genovese, "IL-17 receptor and its functional significance in psoriatic arthritis," Molecular and Cellular Biochemistry, vol. 359, no. 1-2, pp. 419-429, 2012.

[77] M. I. Koenders, E. Lubberts, B. Oppers-Walgreen et al., "Blocking of interleukin-17 during reactivation of experimental arthritis prevents joint inflammation and bone erosion by decreasing RANKL and interleukin-1," The American Journal of Pathology, vol. 167, no. 1, pp. 141149, 2005.

[78] S. Kotake, N. Udagawa, N. Takahashi et al., "IL-17 in synovial fluids from patients with rheumatoid arthritis is a potent stimulator of osteoclastogenesis," The Journal of Clinical Investigation, vol. 103, no. 9, pp. 1345-1352, 1999.

[79] M. A. Lowes, T. Kikuchi, J. Fuentes-Duculan et al., "Psoriasis vulgaris lesions contain discrete populations of Th1 and Th17 T cells," The Journal of Investigative Dermatology, vol. 128, no. 5, pp. 1207-1211, 2008.

[80] J. Pene, S. Chevalier, L. Preisser et al., "Chronically inflamed human tissues are infiltrated by highly differentiated Th17 lymphocytes," The Journal of Immunology, vol. 180, no. 11, pp. 7423-7430, 2008.

[81] A. M. Lin, C. J. Rubin, R. Khandpur et al., "Mast cells and neutrophils release IL-17 through extracellular trap formation in psoriasis," The Journal of Immunology, vol. 187, no. 1, pp. 490-500, 2011.

[82] O. J. de Boer, J. J. van der Meer, P. Teeling et al., "Differential expression of interleukin-17 family cytokines in intact and complicated human atherosclerotic plaques," The Journal of Pathology, vol. 220, no. 4, pp. 499-508, 2010.

[83] F. Villanova, B. Flutter, I. Tosi et al., "Characterization of innate lymphoid cells in human skin and blood demonstrates increase of NKp44+ ILC3 in psoriasis," The Journal of Investigative Dermatology, vol. 134, no. 4, pp. 984-991, 2014.

[84] N. L. Ward and D. T. Umetsu, "A new player on the psoriasis block: IL-17A- and IL-22-producing innate lymphoid cells," The Journal of Investigative Dermatology, vol. 134, no. 9, pp. 2305-2307, 2014.

[85] S. Pantelyushin, S. Haak, B. Ingold et al., "Ror $\gamma \mathrm{t}^{+}$innate lymphocytes and $\gamma \delta \mathrm{T}$ cells initiate psoriasiform plaque formation in mice," The Journal of Clinical Investigation, vol. 122, no. 6, pp. 2252-2256, 2012.

[86] R. G. Langley, B. E. Elewski, M. Lebwohl et al., "Secukinumab in plaque psoriasis-results of two phase 3 trials," The New England Journal of Medicine, vol. 371, no. 4, pp. 326-338, 2014.

[87] A. Blauvelt, K. Reich, T. F. Tsai et al., "Secukinumab is superior to ustekinumab in clearing skin of subjects with moderate-to-severe plaque psoriasis up to 1 year: results from the CLEAR study," Journal of the American Academy of Dermatology, vol. 76, no. 1, pp. 60-69.e9, 2017.

[88] K. B. Gordon, A. Blauvelt, K. A. Papp et al., "Phase 3 trials of ixekizumab in moderate-to-severe plaque psoriasis," The New England Journal of Medicine, vol. 375, no. 4, pp. 345356, 2016.

[89] P. J. Mease, D. van der Heijde, C. T. Ritchlin et al., "Ixekizumab, an interleukin-17A specific monoclonal antibody, for the treatment of biologic-naive patients with active psoriatic arthritis: results from the 24-week randomised, double-blind, placebo-controlled and active (adalimumab)-controlled period of the phase III trial SPIRIT-P1," Annals of the Rheumatic Diseases, vol. 76, no. 1, pp. 79-87, 2017. 
[90] M. Lebwohl, B. Strober, A. Menter et al., "Phase 3 studies comparing brodalumab with ustekinumab in psoriasis," The New England Journal of Medicine, vol. 373, no. 14, pp. 1318-1328, 2015.

[91] K. A. Papp, K. Reich, C. Paul et al., "A prospective phase III, randomized, double-blind, placebo-controlled study of brodalumab in patients with moderate-to-severe plaque psoriasis," British Journal of Dermatology, vol. 175, no. 2, pp. 273-286, 2016.

[92] I. B. McInnes, J. Sieper, J. Braun et al., "Efficacy and safety of secukinumab, a fully human anti-interleukin-17A monoclonal antibody, in patients with moderate-to-severe psoriatic arthritis: a 24-week, randomised, double-blind, placebocontrolled, phase II proof-of-concept trial," Annals of the Rheumatic Diseases, vol. 73, no. 2, pp. 349-356, 2014.

[93] D. Poddubnyy, K. G. Hermann, J. Callhoff, J. Listing, and J. Sieper, "Ustekinumab for the treatment of patients with active ankylosing spondylitis: results of a 28 -week, prospective, open-label, proof-of-concept study (TOPAS)," Annals of the Rheumatic Diseases, vol. 73, no. 5, pp. 817-823, 2014.

[94] K. Eyerich, V. Dimartino, and A. Cavani, "IL-17 and IL-22 in immunity: driving protection and pathology," European Journal of Immunology, vol. 47, no. 4, pp. 607-614, 2017.

[95] T. Korn, E. Bettelli, M. Oukka, and V. K. Kuchroo, "IL-17 and Th17 cells," Annual Review of Immunology, vol. 27, no. 1, pp. 485-517, 2009.

[96] S. Rutz, C. Eidenschenk, and W. Ouyang, "IL-22, not simply a Th17 cytokine," Immunological Reviews, vol. 252, no. 1, pp. 116-132, 2013.

[97] W. Ouyang, J. K. Kolls, and Y. Zheng, "The biological functions of T helper 17 cell effector cytokines in inflammation," Immunity, vol. 28, no. 4, pp. 454-467, 2008.

[98] Y. Zheng, D. M. Danilenko, P. Valdez et al., "Interleukin22, a $\mathrm{T}_{\mathrm{H}} 17$ cytokine, mediates IL-23-induced dermal inflammation and acanthosis," Nature, vol. 445, no. 7128, pp. 648-651, 2007.

[99] H. Benham, L. M. Rehaume, S. Z. Hasnain et al., "Interleukin23 mediates the intestinal response to microbial $\beta$-1,3-glucan and the development of spondyloarthritis pathology in SKG mice," Arthritis \& Rhematology, vol. 66, no. 7, pp. 1755-1767, 2014.

[100] A. Mitra, S. K. Raychaudhuri, and S. P. Raychaudhuri, "Functional role of IL-22 in psoriatic arthritis," Arthritis Research \& Therapy, vol. 14, no. 2, article R65, 2012.

[101] A. A. El-Zayadi, E. A. Jones, S. M. Churchman et al., "Interleukin-22 drives the proliferation, migration and osteogenic differentiation of mesenchymal stem cells: a novel cytokine that could contribute to new bone formation in spondyloarthropathies," Rheumatology, vol. 56, no. 3, pp. 488-493, 2017. 


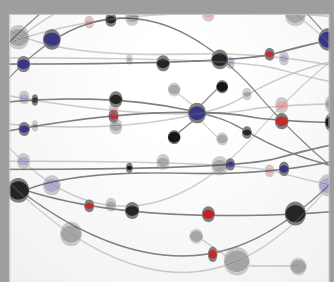

The Scientific World Journal
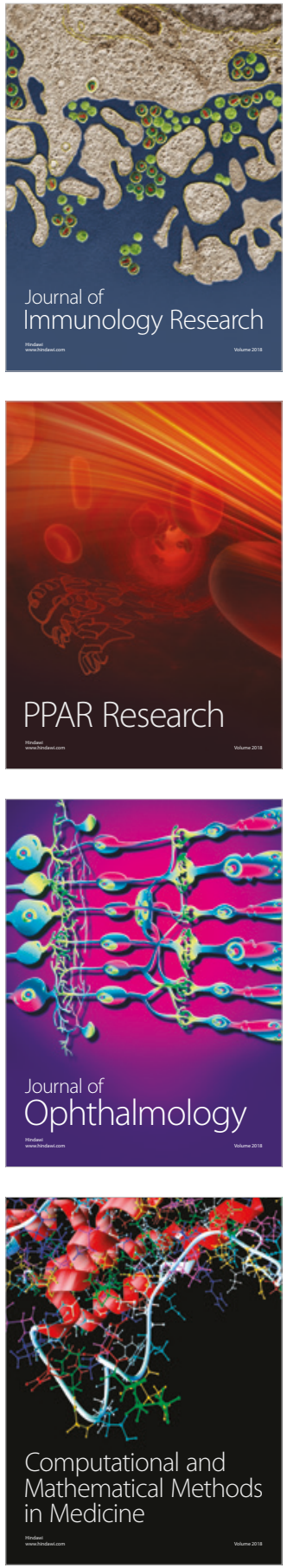

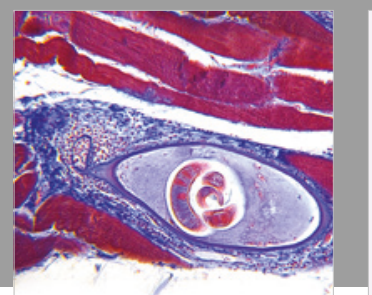

Gastroenterology Research and Practice

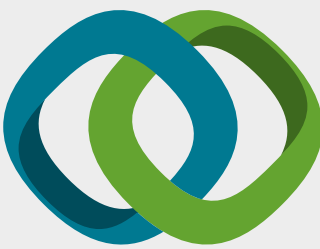

\section{Hindawi}

Submit your manuscripts at

www.hindawi.com
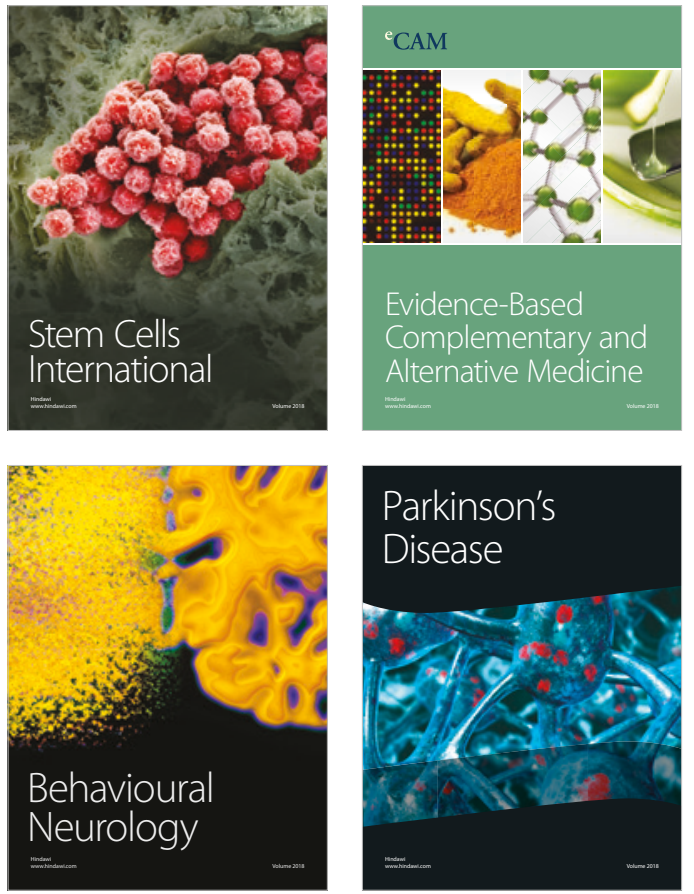

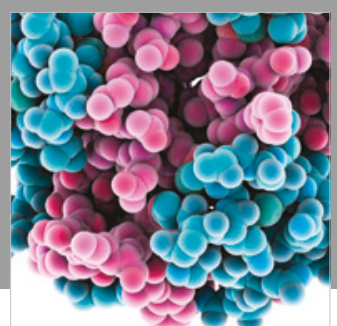

ournal of

Diabetes Research

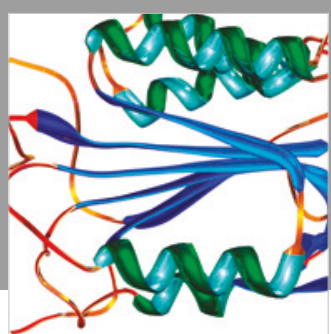

Disease Markers
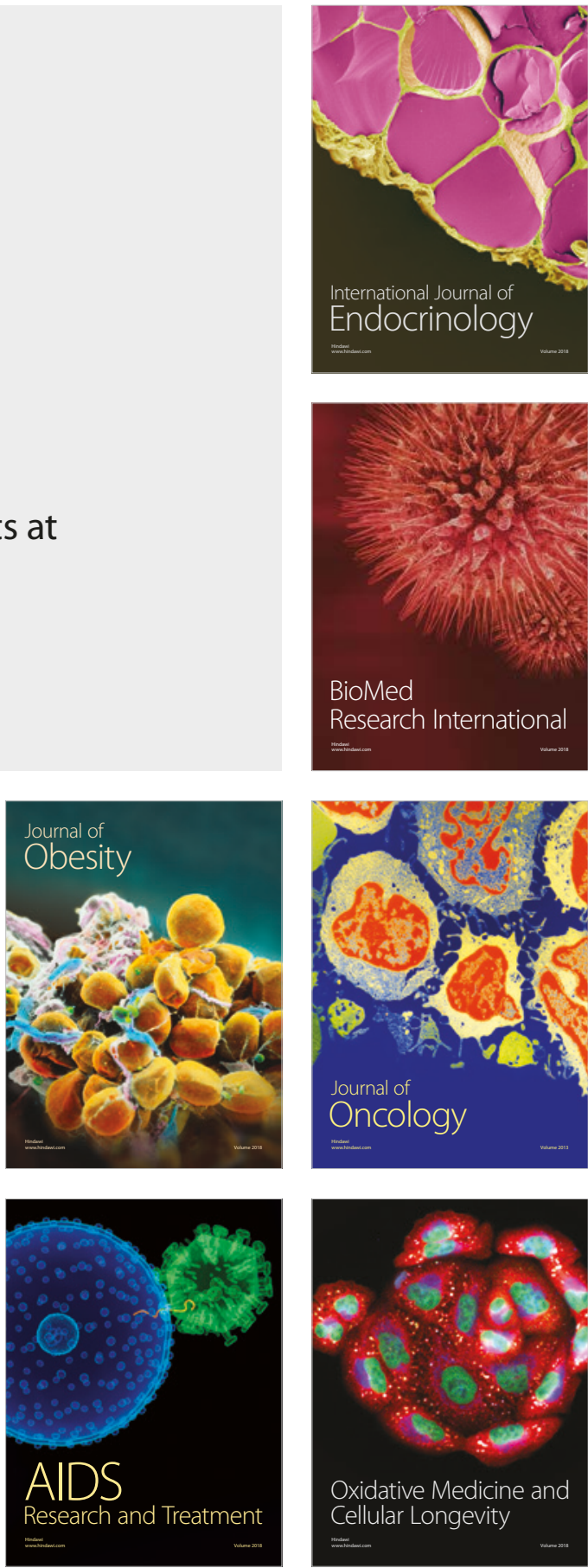